\title{
Morphological study of myocardial capillaries in endurance trained rats
}

\author{
Qu Xia, MA \\ Department of Anatomy, Beijing Institute of Physical Education, Beijing, China
}

\begin{abstract}
In this morphological study of the effects of training on myocardial capillaries, four week old Wister rats were selected to accept four months of treadmill training. The rats were then sacrificed for morphological study of myocardial capillaries by means of perfused Chinese ink, AKP stain and ultrathin section methods. The results showed that the number of capillaries in trained rats was increased markedly by 14.8 per cent $(P<0.05)$ in the outer layer and 13.7 per cent $(P<0.05)$ in the inner layer. The ratio of capillaries to myocardial fibres was increased by 17.6 per cent and 13.7 per cent $(P<0.05)$ respectively. The area and girth of capillaries in the trained rats were increased by 25 per cent and 26 per cent $(P<0.01)$ respectively. Collateral branches in the trained rats were also increased and were more irregular in shape or appeared locally expanding and tortuous. Unopened capillaries were often observed in the control rats, while in the trained rats, no unopened capillaries were observed. In addition, the small vacuoles in the cytoplasm of endothelial cells were also increased.
\end{abstract}

Keywords: Endurance training, rats, myocardial capillaries, morphology

Numerous studies have shown that exercise may improve and increase the adaptation capacity of the cardiovascular system ${ }^{1,2}$. At the same time, the ability of the heart to withstand a variety of stress can be enhanced ${ }^{3,4}$. Numerous animal experiments have shown that capillary density and the ratio of capillaries to myocardial fibres have increased after exercised training in rats ${ }^{5-11}$. In recent years, electron microscopy has been used to study changes in myocardial capillaries in exercised rats ${ }^{12-15}$. This study further probes the growth of myocardial capillaries combined with the morphological and structural changes.

\section{Method}

The animal groups are described in Table 1.

A total of 30 four week old male Wistar rats were obtained for this study. There were five rats to a cage. The animals could eat and drink freely. A mixed diet

Address for correspondence: Qu Xia, Department of Obstetrics and Gynaecology, Third Hospital, Beijing Medical University, Beijing 100083, People's Republic of China.

(C) 1990 Butterworth-Heinemann Ltd 0306-4179/90/020113-04
Table 1. Animal groups

\begin{tabular}{lccc}
\hline & $\begin{array}{c}\text { Perfused } \\
\text { ink }\end{array}$ & Histochemical & $\begin{array}{c}\text { Ultrathin } \\
\text { section }\end{array}$ \\
\hline Trained group & 5 & 5 & 5 \\
Control group & 5 & 5 & 5 \\
\hline
\end{tabular}

was used. The food was obtained from the Department of Animal Experiment in Beijing Medical University. The training programmes are described in Table 2. Rodent treadmills were made in our laboratories.

The treadmill speed was accurately controlled between $0-45 \mathrm{~m} / \mathrm{min}$, and the slope was changed by 0-15 degree units. We randomised the groups before training. The training volume was progressively increased by increasing the speed and slope or duration of the treadmill run. When the final workload was reached, the animals were maintained at that level until they were sacrificed.

\section{Preparation}

Four grammes of gelatin was melted into $100 \mathrm{ml}$ of distilled water to make a four per cent gelatin solution. This was mixed with $100 \mathrm{ml}$ of Chinese ink to make the perfusion. Just before sacrifice, all animals were anaesthetized with ether and the thorax opened. The aorta was then cannulated and the perfusion ink liquid was injected at constant perfusion pressure. After perfusion, the heart was removed and fixed in 10 per cent formaldehyde and dehydrated in an ethanol series. Finally, it was embedded in colloidin. The sample was sectioned into $80 \mu \mathrm{m}$ thick rings perpendicular to the axis of the heart from the apex to the base.

Table 2. Endurance training programmes

\begin{tabular}{|c|c|c|c|}
\hline $\begin{array}{l}\text { Time } \\
\text { (months) }\end{array}$ & $\begin{array}{l}\text { Speed } \\
\mathrm{m} / \mathrm{min}\end{array}$ & $\begin{array}{c}\text { Grade, } \\
\text { degrees }\end{array}$ & $\begin{array}{l}\text { Training } \\
\text { time, } \min \end{array}$ \\
\hline $\begin{array}{l}\text { First month } \\
\text { Second month } \\
\text { Third month } \\
\text { Fourth month }\end{array}$ & $\begin{array}{l}15 \\
23 \\
25 \\
25\end{array}$ & $\begin{array}{l}0 \\
5 \% \\
10 \% \\
10 \%\end{array}$ & $\begin{array}{l}60 \\
60 \\
60 \\
60\end{array}$ \\
\hline
\end{tabular}


The myocardial samples were mounted in an embedding medium and frozen in isopentane cooled to freezing point. Serial transverse sections $(10 \mu$ thick) were cut in a cryostat at $-20^{\circ} \mathrm{C}$. Sections were stained for ATP, AKP and acid phosphatase.

Just before sacrifice, all animals were anaesthetized with ether and the thorax was opened. Each rat heart was cut rapidly into $2 \mathrm{~mm}$ thick slices. The free wall of each ventricle was sliced transversely into several blocks. The blocks were fixed on three per cent glutaraldehyde at $4^{\circ} \mathrm{C}$ for 1.5 hours, washed in buffer, postfixed in 0.3 per cent $\mathrm{OsO} 4$ for between one and two hours, dehydrated with acetone and embedded in 613 epoxy resin. Five tissue blocks were chosen at random from each ventricle, located and then ultrasectioned. The sections were examined by electron microscopy for myocardial capillary composition. Ten photomicrographs of randomly selected ultrathin sections were taken from each block at 10,000 magnification.

\section{Results}

Changes in heart weight and capillary density are shown in Tables 3 and 4.

The myocardium is very rich in capillaries. The majority of capillaries run parallel to the myocardial fibres. Ramifications and anastomoses form a capillary network. The capillaries in the control group are very regular and the lumena are very even. At the same time, the capillaries of the control group are straight. In the trained group, the number of capillaries in the myocardium is increased. We can see from injection sections that there are more capillaries than in the control group. Compared with the controls, they present a more tortuous arrangement, the capillaries are anastomosed and show regional enlargement.

Figure 1 shows the structure of the cardiac capillaries in the control group. Endothelial cells

Table 3. Heart weight

\begin{tabular}{llll}
\hline & \multicolumn{1}{c}{ Trained } & \multicolumn{1}{c}{ Control } & Change \\
\hline No. of rats & 5 & 5 & \\
Body wt (g) & $478 \pm 40.87$ & $458 \pm 44.81$ & $+4.4 \%$ \\
$\begin{array}{l}\text { Heart wt (g) } \\
\text { Heart wt/ }\end{array}$ & $1.63 \pm 0.16$ & $1.49 \pm 0.16$ & $+9.4 \%$ \\
body wt & $1.34 * 10 \pm 0.01 * 10$ & $0.32 * 10 \pm 0.01 * 10$ & $+6.2 \%$ \\
\hline
\end{tabular}

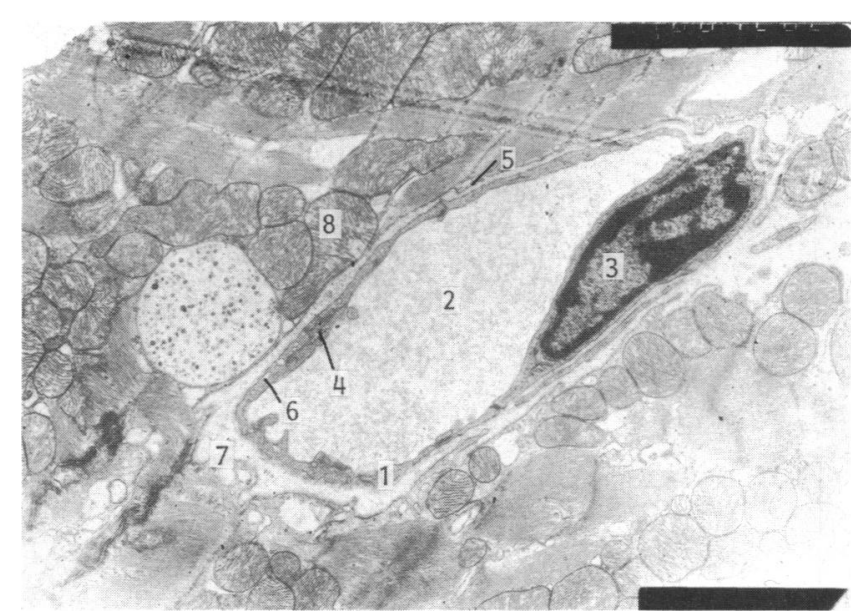

Figure 1. Cross section of capillary in cardiac muscle. 1 Capillary wall, 2 Lumen, 3 Nucleus of endothelial cell, 4 Junction, 5 Basal lamina, 6 Vesicle, 7 Pericapillary connective tissue space, 8 Mitochondrion in myocardial cell

show cell membrane, cytoplasm and nucleus. The ends of the plasma membrane have joined endothelial cells to enclose the tube structure to form the capillary. The endothelial cytoplasm has organelles. The vesicular structure indicates related transport in the cytoplasm.

Figure 2 shows an unopened capillary from the control group. Endothelial cells of these kind of

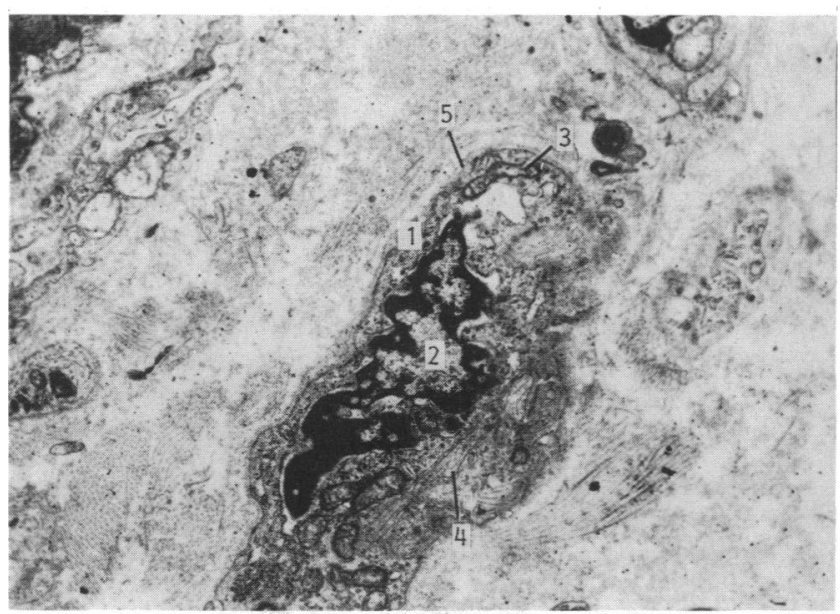

Figure 2. Cross section of unopened myocardial capillary. 1 Endothelial cytoplasmic membrane, 2 Endothelial cell nucleus, 3 Mitochondrion in endothelial cytoplasm, 4 Microfibre and microtube, 5 Basal lamina

Table 4. Capillary density

\begin{tabular}{|c|c|c|c|c|c|}
\hline & & Trained & Control & Change & $P$ \\
\hline $\begin{array}{l}\text { Extramyocardial layer } \\
\text { Intramyocardial layer } \\
\text { Extramyocardial layer } \\
\text { Extramyocardial layer } \\
\text { Intramyocardial layer } \\
\text { Intramyocardial layer } \\
\text { Cap. lumen area } \mu \mathrm{m} \\
\text { Cap. perimeter } \mu \mathrm{m}\end{array}$ & $\begin{array}{l}\text { root } / \mathrm{mm}^{2} \\
\text { root } / \mathrm{mm}^{2} \\
\text { fibre } / \mathrm{mm}^{2} \\
\text { cap } / \mathrm{fib} / \mathrm{mm}^{2} \\
\text { fibre } / \mathrm{mm}^{2} \\
\text { cap } / \mathrm{fib} / \mathrm{mm}^{2}\end{array}$ & $\begin{array}{l}2140 \pm 181.66 \\
2104 \pm 135.20 \\
1789 \pm 151.63 \\
1.1962 \\
1614 \pm 103.39 \\
1.3036 \\
12.59 \pm 0.91 \\
20.83 \pm 3.2\end{array}$ & $\begin{array}{l}1864 \pm 127.59 \\
1850 \pm 87.8 \\
1832 \pm 125.48 \\
1.0175 \\
1756 \pm 82.85 \\
1.0535 \\
10.07 \pm 1.345 \\
16.48 \pm 1.36\end{array}$ & $\begin{array}{l}+14.8 \% \\
+13.7 \% \\
-2.3 \% \\
+17.6 \% \\
-8 \% \\
+23.7 \% \\
+25 \% \\
+26 \%\end{array}$ & $\begin{array}{l}<0.05 \\
<0.05 \\
=0.123 \\
<0.05 \\
<0.05 \\
<0.05 \\
<0.01 \\
<0.01\end{array}$ \\
\hline
\end{tabular}




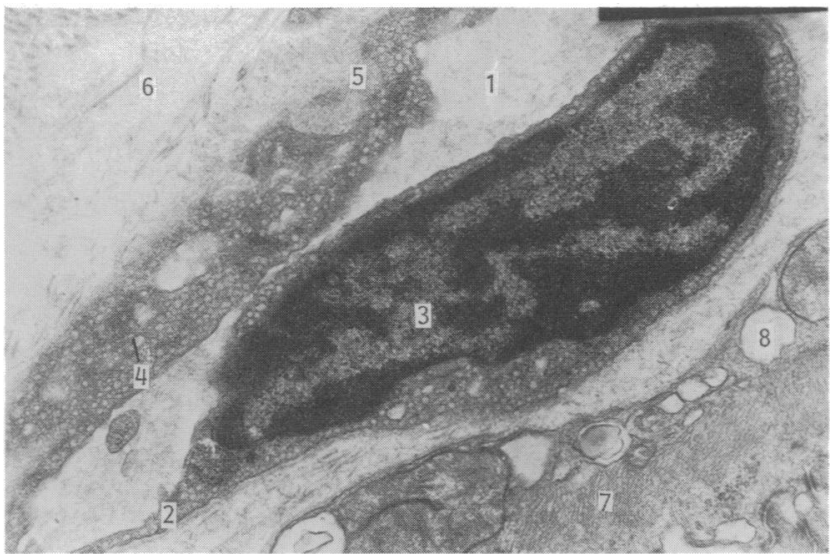

Figure 3. Cross section of capillary in heart (trained group). 1 Capillary lumen, 2 Capillary wall, 3 Endothelial cell nucleus, 4 Vesicle, 5 Endothelial endocytosis,

6 Pericapillary connective tissue, 7 Part of myocardial fibre, 8 Sarcoplasmic reticulum

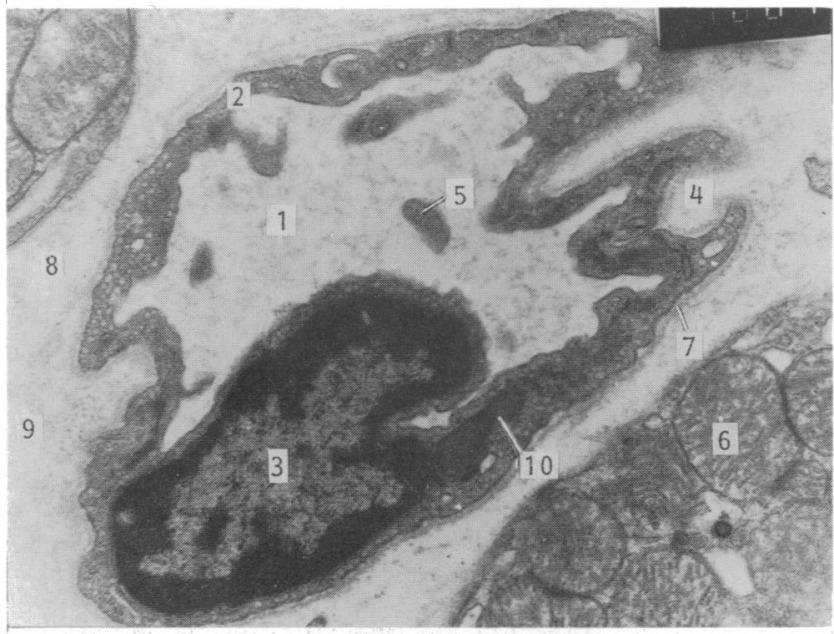

Figure 4. Cross section of heart (trained group).

1 Capillary lumen, 2 Capillary wall, 3 Endothelial cell nucleus, 4 Endocytosis, 5 Endocytosic material, 6 Mitochondrion, 7 Basal lamina, 8 Pericapillary connective tissue space, 9 Myocardial fibre, 10 Mitochondrion

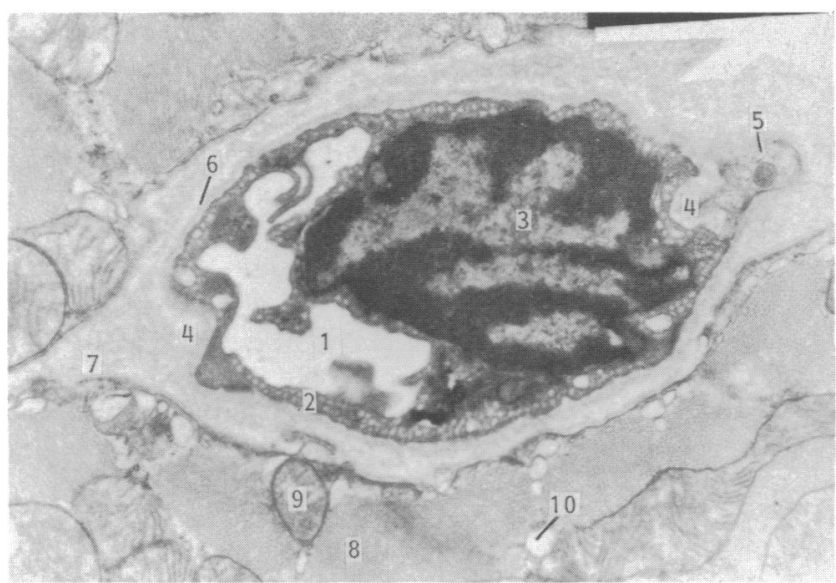

Figure 5. Cross section of heart (trained group). 1 Capillary lumen, 2 Capillary wall, 3 Endothelial cell nucleus, 4 Exocytosis phenomenon, 5 Exocytosic material, 6 Basal lamina, 7 Pericapillary connective tissue space, 8 Myocardial fibre, 9 Mitochondrion, 10 Sarcoplasm reticulum

\section{Myocardial capillaries in endurance trained rats: $\mathbf{Q u}$ Xia}

capillary have the same abundant cell organelles, but the lumen has vanished.

Figures 3, 4 and 5 show that most capillaries in the trained group have the same structure as in the control group, but the number and size of the vesicles has increased. At the same time, the walls of the capillary show evidence of exocytosis and endocytosis.

Figures 6,7 and 8 show some changes in the structure of the capillaries in the trained group. A part of the capillary lumen shows irregularity. Plasma membrane projects into the lumen and overlaps to form a new area. Some plasma membranes mosaic with each other and form new lumena. In such a lumen, the plasma membrane is very thick. There were some hyperchromatic materials adherent to plasma membrane and the vesicles are not abundant.

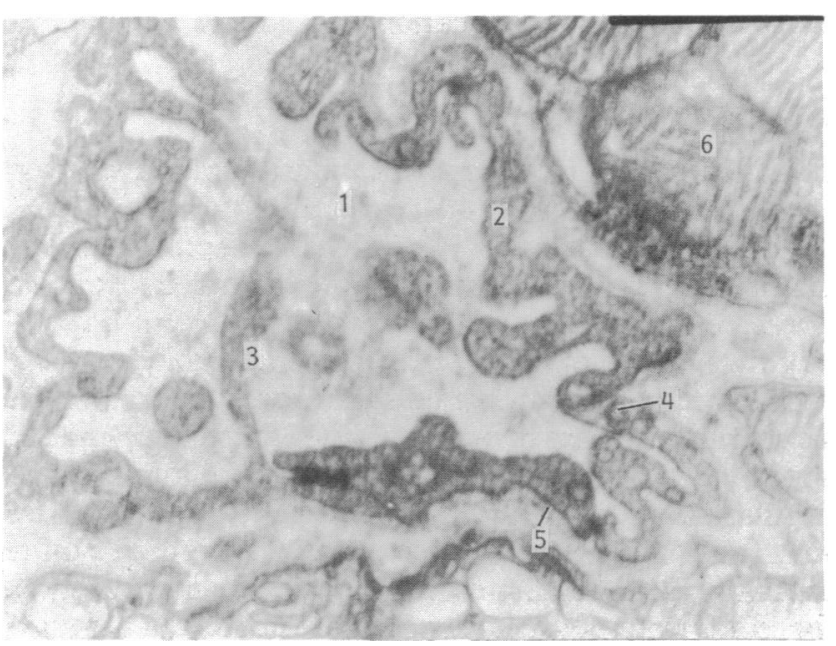

Figure 6. Cross section of newly formed heart capillary (trained group). Endothelial cytoplasm membrane projecting into lumen with a fold forming the irregular lumen termed the primary capillary. 1 Capillary lumen, 2 Endothelial cytoplasmic membrane, 3 Cytoplasm membrane projecting, 4 Vesicle, 5 Basal lamina, 6 Mitochondrion

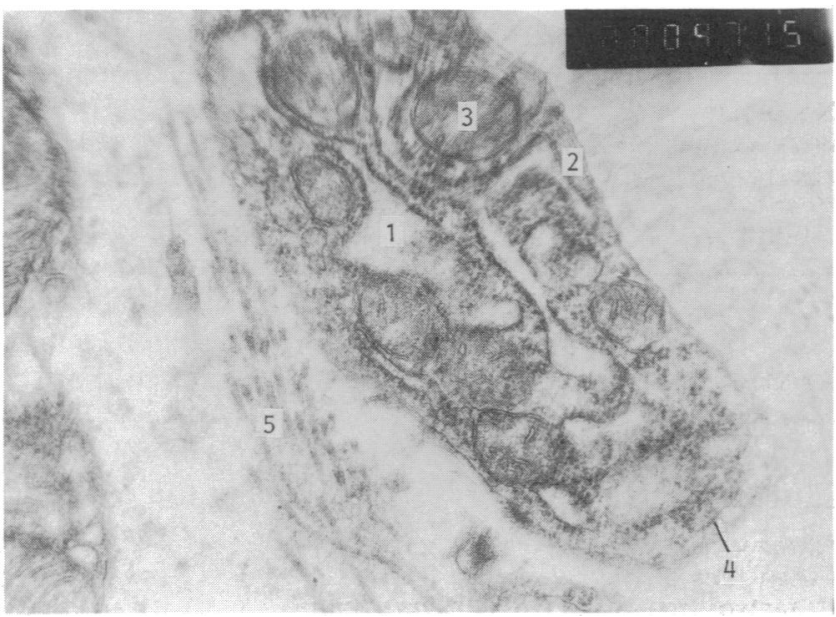

Figure 7. Cross section of newly formed heart capillary (trained group). Cytoplasmic membrane connecting to produce second capillary. 1 New capillary lumen, 2 Capillary wall, 3 Mitochondrion, 4 Basal membrane, 5 Interendothelial fibre 


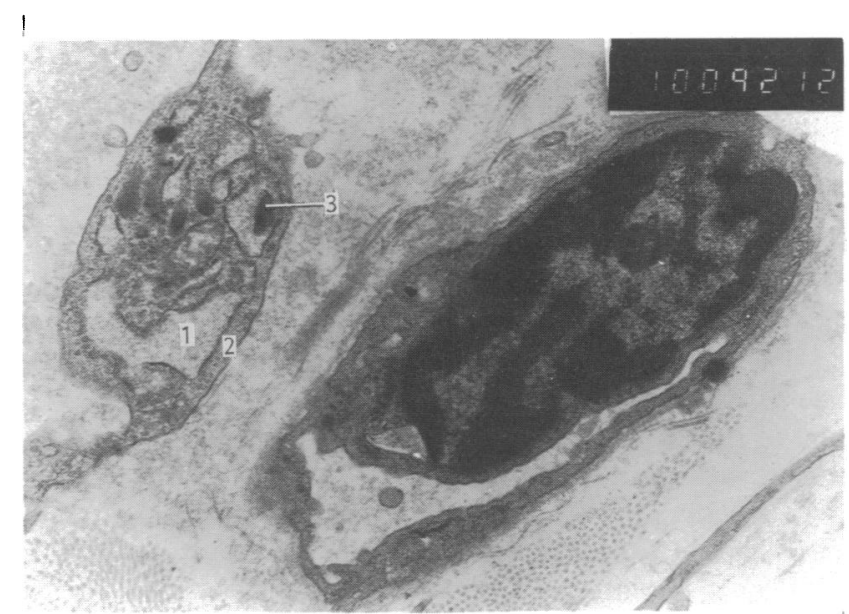

Figure 8. Cross section of heart. On right - new capillary. 1 New capillary lumen, 2 New capillary wall, 3 Hyperchromatic substance

\section{Discussion}

In this study, male rats performed endurance training by a treadmill programme consisting of one hour per day, five days per week for 16 weeks. An initial study showed that this programme produced training effects. When compared with the control group, exercised rats showed significant changes.

As is commonly known, there is a wealth of capillaries in the myocardium. After four-month endurance training, capillary density is increased significantly. Thus, endurance training induces an increase in the activity of oxidative enzymes which produces the increase in capillary density related to the individual cardiac fibres.

There are two views regarding the change in number of myocardium capillaries. First, in general, all capillaries are not patent at the same time. Only 20 per cent of capillaries are open at rest. Local metabolites increase with frequency, intensity and duration of the training session, and according to the age, sex, and strain of the rats used. The majority of capillaries open to adapt to the necessary metabolic level. The more the training, the more capillaries are opened. Second, while opened capillary are maintained and unopened capillary are reopened in the trained grup, there is some regeneration of capillaries at the same time. In this study, electron microscopy shows that not only do unopened capillaries reopen, but also capillary regeneration is produced. So it is evident that the change in the number of capillaries is due to closed capillaries and the regeneration opening of capillaries produced in endurance-trained rats.

How is this regenerated capillary formed? Ji and Chuan reported that endothelial cells of the capillary fold into the capillary lumen to connect with corresponding endothelial cells in order to separate the lumen into two endothelial beds ${ }^{16}$. In this study, it is clear that endurance training stimulates the capillary wall to make endothelial cytoplasmic membrane projections into the lumen which curl to produce the irregular shapes. The endothelia fuse to form the lumen of the new capillary. The projecting cytoplasmic membrane forms buds which gradually form into cords. So one can infer that it forms a new lumen or primary capillary through the onrush of blood. In time, the primary becomes the secondary capillary, with the same structure as the control capillary. Although workers have different views on the regeneration of capillaries, it is certain that this kind of capillary regeneration is due to endothelial cell division and curling of the plasma membrane which connects to the opposite plasma membrane to produce the new lumen. Also, there are abundant organnelles and hyperchromatic material in the regenerative capillary. At the same time there is active exocytosis and endocytosis in the secondary capillary of trained rats. It is evident that the endothelial cells of the capillary wall are in attitudes of active function, and are gradually adapting to the training requirements.

\section{References}

1 Blomqvist, C.G. and Saltin, B. Cardiovascular adaptation to physical training Ann Rev Physiol 1983, 45, 169

2 Scheuer, J. and Tiption, C.M. Cardiovascular adaption to physical training Ann Rev Physiol 1977, 39, 221

3 Dowel, R.T. Heart functional response to pressure overload in exercised and sedentary rats $A m$ J Physiol 1976, 230, 199

4 McElory, C.L. Exercise-induction in myocardial infarct size after coronary artery occlusion in the rat Circulation 1978, 57, 958

5 Petre, T. Der Einflub des Trainings auf die Haufigkeit der capillaren in Herz and Skeletmuskulatur Arbeitphysiologie 1936, 9, 376-386

6 Blood, C.M. Interaction of age and exercise on the heart and its blood supply Lab Invest 1970, 22, 160-15

7 Wachtiove, M. et al. The coronary terminal vascular bed in the heart of the hare and the rabbit Physiol Bohemoslove 1965, 14, 328-331

8 Poupa, O. and Rakusan, K. The terminal microcirculatory bed in the heart of the athletic and non-athletic animal In 'Physical Activity in Health and Disease' Edited by K, Evang and K.LO. Andersen, Oslo, Universitets-forlaget, 1966, 18-29

9 Stevenson, J.A.F. et al. Effect of exercise on coronary tree size in the rat Circ Res 1964, 15, 265-269

10 Denenber, D.L. The effects of exercise on the coronary collateral circulation J Sports Med Phys Fitness 1972, 18, 76-81

11 Tepperman, J. and Pearlman, D. Effects of exercise and anaemia on coronary arteries of small animals as revealed by the corrosion cast technique Cire Res 1961, 11, 576-584

12 Ljungqvist, $A$. The proliferativer activity of the myocardial tissue in various forms of experimental cardiac hypertrophy Acta Pathol Microbiol Scand 1973, 8, 233-240

13 Ljungqvist, A. Capillary proliferative activity in myocardium and skeletal muscle of exercised rats $J$ Appl Physiol 1977, 43, 306-307

14 Mandache, E. Myocardial blood capillary reaction in various forms of cardiac hypertrophy. An electron microscopical investigation in the rat Virohoes Arch (Zellpathol) 1970, 11, 97-110

15 Mandache, E. The proliferative activity of the heart tissue in various forms of experimental cardiac hypertrophy studied by electron microscope autoradiography Virchows Arch (Zellpathol) 1973, 12, 112-122 